\title{
ANALISANDO UMA PROPOSTA DE ALINHAMENTO ENTRE O SUPRIMENTO E A DEMANDA: O CASO DO SETOR DE GASES INDUSTRIAIS NO BRASIL
}

\section{ANALYSING A SUPPLY AND DEMAND ALIGNMENT PROPOSAL: THE CASE OF THE BRAZILIAN INDUSTRIAL GAS MARKET}

\author{
Luiz Carlos Brasil de Brito Mello \\ Engenheiro, MsC., Doutorando
}

Programa de Pós Graduação em Engenharia Civil - Universidade Federal Fluminense

Av. General San Martin 646/501-Leblon, Rio de Janeiro

Tel. 21-25122342 - e-mail: luiz.brasil@gmail.com

\section{Renata Albergaria de Mello Bandeira}

Engenheira, Mestranda em Engenharia de Produção

Programa de Pós Graduação em Engenharia de Produção - Universidade Federal do Rio Grande do Sul

Av. Lajeado 140/303 - Porto Alegre, Rio Grande do Sul

Tel. 21-91279340- email: renata@producao.ufrgs.br

\author{
Sérgio Leusin, Dr \\ Arquiteto,_Doutor em Engenharia de Produção
}

Programa de Pós Graduação em Engenharia Civil - Universidade Federal Fluminense.

Av. General San Martin-646/501-Leblon, Rio de Janeiro.

Tel. 21-25122342- email: leusin@ism.com.br 


\title{
RESUMO
}

Este trabalho tem como objetivo pedagógico, estudar a proposta de implantação de um sistema de gestão suprimentos-demanda em uma grande empresa de gases industriais, e comparar esta proposta com a produção científica atual sobre o tema. Como resultado desta comparação, serão expostas sugestões que possam otimizar esta implantação, ou, validá-la, caso esteja atualizada. Desta forma, este ensaio procurará apresentar dentro do cubo de dificuldade (Farias Filho, 2003), em sua dimensão analítica, a oportunidade do leitor avaliar a decisão tomada pela empresa em relação à proposta a ser implementada para otimizar a gestão da cadeia suprimentos-demanda, bem como identificar os possíveis problemas e desafios a serem enfrentados. Em relação à dimensão conceitual, o trabalho aborda as principais teorias pertinentes ao tema desenvolvido através de uma apresentação teórica bastante ampla. Em última instância, na dimensão apresentação, o texto procura expor de forma simples algumas informações referentes à empresa, de modo a possibilitar ao leitor uma melhor compreensão dos objetivos levantados e julgamento das sugestões e conclusões pertinentes às duas dimensões abordadas anteriormente.

Palavras-chave: Logística, gestão suprimento-demanda, gases industriais.

\begin{abstract}
This text aims at analyzing the proposed implantation of a supply-demand alignment system on an important industrial gas company, and in comparing this proposal with the literature related to subject. As result of this comparison, there will be presented suggestions in attempt to validate or improve this implantation. Therefore, this essay offers the reader the opportunity to evaluate the decision taken by the company in relation to the proposal to be implemented, as well as identifying the problems and challenges to be faced. The theoretical aspects concerning the subject are also stressed. Finally, the text presents some referring information to the company, in order to make it possible to the reader a better understanding of the raised objectives and judgment of the pertinent suggestions and conclusions.
\end{abstract}

Key-words: Logistics, supply-demand alignment, industrial gas.

\section{INTRODUÇÃO}

Para sobreviver à nova ordem econômica, as organizações precisam adaptar-se à realidade competitiva e tecnológica atual, bem como aprender a identificar, ganhar e preservar novos mercados. $\mathrm{O}$ aumento da demanda por melhores serviços, qualidade e variedade de 
produtos, associado ao crescimento da concorrência, tem levado as organizações a repensar a maneira como gerenciam seus negócios.

O gerenciamento da cadeia de suprimentos tornou-se uma iniciativa estratégica para empresas que pretendem aumentar seu potencial competitivo. Nos últimos anos, é crescente no Brasil a discussão sobre projetos de gerenciamento da cadeia de suprimentos, principalmente com a utilização de ferramentas SCM (Supply Chain Management). Há um esforço grande das empresas em buscar uma integração da cadeia de valor, um processo de colaboração que une as atividades internas e externas, entregando maior valor percebido até o cliente final.

Nesse sentido, as empresas começaram a buscar novas formas e alternativas de fornecimento, processamento e distribuição dos seus produtos e serviços, na tentativa de diferenciar-se e aumentar a percepção de valor dos seus clientes. Assim, no final da década de 90, a logística tornou-se um assunto-alvo na academia, implicando o surgimento de vários estudos e pesquisas na área de gestão de empresas.

Este estudo tem como objetivo geral, realizar uma avaliação da proposta de implementação de um sistema de gerenciamento suprimentos-demanda pela empresa de gases industriais analisada, comparando-o com o estágio atual do conhecimento nesta área. São apresentadas propostas de melhorias que, se adotadas, devem contribuir para a otimização da aplicação deste sistema.

O paper pretende ater-se ao modelo de gestão proposto pela empresa, estudando sua viabilidade de aplicação e respondendo as seguintes questões: $(i)$ como a empresa pretende integrar o gerenciamento da cadeia de suprimentos com o gerenciamento da cadeia de demanda; (ii) como a proposição é suportada pelo conhecimento técnico-científico atual em relação ao assunto; e (iii) quais sugestões podem ser dadas para melhorar a proposta de implantação existente. 


\section{CONTEXTUALIZAÇ̃̃ DA LOGÍSTICA}

Com base no Council of Logistics Management_(2004), logística é o processo de

planejamento, implementação e controle eficiente e eficaz do fluxo e armazenagem de mercadorias, serviços e informações relacionadas desde o ponto de origem até o ponto de consumo, com o objetivo de atender às necessidades do cliente. Há bem pouco tempo, o conceito de logística era confundido com as áreas de transporte ou de abastecimento. Esse era o paradigma vigente. Contudo, esta situação está se alternando, pois esta é uma das áreas da disciplina de Administração que mais tem se expandido nos últimos anos.

Williams, Nibbs \& Irby (1997) observam que a partir da década de 70, a logística integrada passa a ser percebida como um dos componentes da estratégia empresarial. Desta forma, a rede logística deixa de ser considerada apenas sobre o aspecto da operação, e passa a desempenhar um papel estratégico que, quando bem administrado, torna-se uma vantagem competitiva. Segundo Christopher (1997), o gerenciamento da Logística tem potencial para auxiliar a alcançar tanto a vantagem em custo/produtividade como a vantagem em valor. $\mathrm{O}$ grande desafio é manter vantagens competitivas duradouras num mundo em constante mudança.

As forças do ambiente de negócios que influenciam o desenvolvimento da Logística são: consumidores cada vez mais exigentes, redução dos ciclos de vida dos produtos, utilização cada vez mais intensiva de processos just in time, globalização e proliferação de itens substitutos. Para que tais obstáculos sejam ultrapassados, uma gestão eficaz da cadeia de suprimentos deve focar na redução dos tempos envolvidos em dois componentes consecutivos: o fluxo da informação do pedido do cliente e o fluxo físico de materiais e produtos (Mason-Jones \& Towil, 1998).

Walker (1998) apresenta um modelo para transformar uma logística centrada na organização individual em uma baseada numa rede colaborativa. $\mathrm{O}$ modelo constitui-se de 
quatro etapas: $(i)$ construir uma infra-estrutura de comunicação, sistemas e processos entre as organizações que se propõem a trabalhar em parceria; (ii) sincronizar continuamente a demanda capturada no ponto de venda com as decisões de oferta ao longo de toda a cadeia de suprimentos; (iii) gerenciar a logística global da rede para que se assegure que o produto esteja sempre se movendo, tanto na direção do consumidor, quanto na logística reversa; (iv) implantar indicadores chave de mensuração, para garantir a satisfação do consumidor final.

É importante ressaltar que nem todas as empresas abordaram a questão logística de forma homogênea. Enquanto algumas empresas conseguiram, através da gestão integrada da logística, alcançar vantagens competitivas sustentáveis e produzir novos negócios, outras ainda consideram a logística como uma atividade de suporte. Em pesquisa realizada pelo Instituto de Movimentação e Armazenagem de Materiais (IMAM, 2002) em empresas de diversos setores, constatou-se que aproximadamente metade das entrevistadas apresenta um departamento de logística formalmente estruturado. Dessas, apenas $2 \%$ têm suas atividades logísticas lideradas pela alta administração, $42 \%$ pelo nível gerencial e o restante pelo nível operacional, fato que justifica o espaço para o desenvolvimento e melhoria no que tange questões estratégicas empresariais.

\section{GERENCIAMENTO DA CADEIA DE SUPRIMENTOS-DEMANDA}

Serão apresentados a seguir os principais conceitos relacionados ao gerenciamento das cadeias de suprimentos e de demanda. Serão levantados os principais pontos referentes ao assunto abordados na literatura relevante.

\subsection{Gerenciamento da Cadeia de Suprimentos}

De acordo com a tendência moderna de integração da logística, a gestão da cadeia de suprimentos considera uma abordagem mais ampla de empresa, que se preocupa tanto com 
aspectos internos, como externos às suas fronteiras. $\mathrm{O}$ conceito de supply chain management (SCM) - gestão da cadeia de suprimentos - tem revolucionado a logística por sucessivamente agregar todos os elementos da cadeia de valor de Porter (COUGHLAN et al,2002).

A gestão da cadeia de suprimentos é um conjunto de abordagens utilizadas para integrar efetivamente fornecedores, fabricantes, depósitos, armazéns e clientes finais, de forma que a mercadoria seja produzida e distribuída na quantidade certa, para a localização certa e no tempo certo, alcançando o menor custo global do sistema a mesmo tempo em que atinge o nível de serviço desejado. Alguns autores situam a Logística como uma parte do SCM. Entretanto, para Novaes (2002), o SCM é "um aprimoramento, ou uma evolução, da Logística”, uma vez que integrou os elementos que participam da cadeia de forma estratégica e sistêmica.

\subsection{Gerenciamento da Demanda}

A demanda de um determinado bem é dada pela quantidade que os compradores desejam adquirir num determinado período de tempo. $\mathrm{O}$ fornecedor não controla a demanda, no entanto, esta tem um impacto significativo na cadeia de suprimentos, sendo influenciada por fatores como nível da atividade econômica, necessidades momentâneas do cliente e preços da concorrência. A gestão da demanda relaciona-se com sua previsão e com as variáveis que podem influenciá-la, tais como o canal de comunicação com o mercado, a habilidade de priorizar e alocar os recursos disponíveis e o cumprimento dos prazos.

A gestão da demanda deve ser de responsabilidade da área comercial (vendas e marketing) em conjunto com a área de planejamento. Caso a gestão fique apenas sob responsabilidade da área comercial, a estimativa pode ser subestimada, de forma que as vendas reais ultrapassem as previsões. Porém, se a previsão for de responsabilidade exclusiva da área de planejamento, estas serão feitas apenas com dados históricos. 

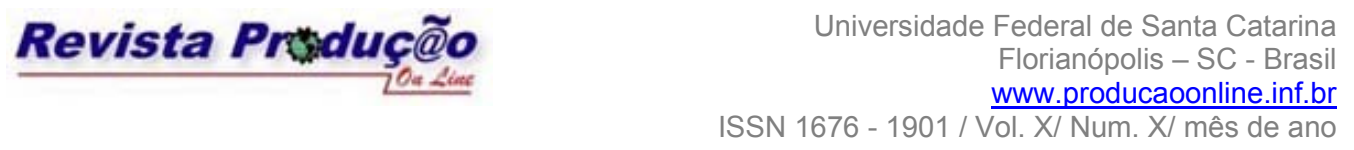

Os gestores podem realizar o acompanhamento da demanda pela produção ou pelo nível de serviço. A primeira opção nem sempre é economicamente viável e de fácil aplicação, já que é um processo que exigirá a ativação ou desativação de recursos à medida que a demanda aumenta ou diminui (Slack, 1997). Segundo Aquino Campos (2003), a estratégia mais recomendada é a de nível de serviço, onde a empresa decide que percentual da demanda máxima esperada quer atender, o comprometimento desejado do nível de serviço, o custo de capitale de oportunidade está disposta a ter.

\subsubsection{A gestão da demanda e a cadeia de suprimentos}

Vários fatores exercem influência sobre a demanda. Descobrir os elementos que condicionam a demanda e entender seus efeitos sobre a cadeia de suprimentos requer coleta de dados, que ajuda a determinação de quais mecanismos são mais efetivos, se a capacidade deve permanecer no nível atual ou crescer e a antever os impactos na cadeia de suprimentos (Bowersox e Closs, 2001). Convém ressaltar que a estratégia de acompanhamento da demanda tem limitações relacionadas à cadeia de suprimentos, uma vez que não é economicamente viável investir e desinvestir em instalações, equipamentos, pessoal, estoques etc (Aquino Campos, 2003).

Ferraes Neto (2000) compara a cadeia de suprimentos a uma corrente, pois, esta será tão forte quanto seu elo mais fraco e um golpe em um dos elos reflete-se nos demais. Se uma das funções falha ou é interrompida, provoca um desbalanceamento de carga nos outros elos da cadeia, diminuindo o desempenho unitário e comprometendo o rendimento total. Assim, erros de previsão de demanda afetam significativamente a cadeia de suprimentos.

\subsubsection{Técnicas de gestão da demanda}

O planejamento da gestão da demanda deve ser iniciado com o plano de previsão de vendas. Este deve ser elaborado com base em dados históricos, informações do pessoal que tem contato com os clientes e informações da imprensa e mercado. Após análise, verifica-se, 
então, a estimativa de consumo no futuro, que pode ser influenciada por propaganda, promoção e prazo de entrega.

O processo de previsão de vendas é muito importante na gestão da demanda, sendo que a incerteza desta previsão, causada pela instabilidade do mercado e pela qualidade do sistema de previsão da organização influencia toda a cadeia logística.

Arozo (2002) prescreve os seguintes procedimentos para previsão de vendas a serem adotados pelas organizações, considerando-se o horizonte de previsão (curto, médio ou longo prazo): a) curto prazo- utiliza-se a hipótese de que o futuro seja uma continuação do passado, ou seja, as mesmas tendências de crescimento ou diminuição observadas no passado , permanecerão no futuro; b) médio prazo- estabelecem-se relações entre as vendas do passado e outras variáveis que expliquem seu comportamento; c) longo prazo- considera-se mudanças tecnológicas, de design e introdução de produtos substitutos.

Para o mesmo autor, as técnicas de previsão de vendas são: a) dados históricos de vendas, período a período; b)dados de variáveis correlacionadas as vendas que ajudem a explicar o comportamento de vendas passadas; c) situação atual de variáveis que podem afetar o comportamento de vendas no futuro; d) informações de clientes que possam indicar tendências de comportamento de compras futuras; e) conhecimento sobre a conjuntura econômica atual e previsão da conjuntura futura; f) informações da área comercial que possam influenciar o comportamento das vendas; g) informações relevantes que possam explicar comportamentos atípicos de vendas passadas.

\subsection{Planejamento colaborativo}

Cada elemento da cadeia de suprimento costumava ter um papel bem delineado: o fornecedor entregava a matéria-prima para o fabricante, que fabricava o produto e distribuía para os varejistas, que comercializavam em suas lojas (Novaes, 2002). Contudo, eşa separação já não é mais nítida. Fornecedores e clientes estão formando parecerias, ao longo da 
cadeia de suprimentos, de modo que haja uma integração plena, estratégica e flexível. Contudo, para que os relacionamentos de cooperação atinjam o sucesso esperado, estes devem ser centrados na intenção real de criar uma cultura orientada para a cadeia de suprimentos (Bowersox e Closs, 2001). Os participantes da cadeia devem compartilhar informações estratégicas, de modo que as empresas possam planejar em conjunto os melhores meios de satisfazer às necessidades.

Para Relvas (1996), a recente adoção de sistemas de planejamento de recursos em larga escala e da Internet, possibilitam de maneira mais eficiente a troca de informações entre fornecedores e clientes. Assim, os esforços das empresas intensificaram-se na busca por processos mais eficazes e pela adoção de sistemas de gestão mais modernos como o ISO 9001: 2000, BSC e outros. Uma empresa não agrega valor somente pelo processamento ou combinação de recursos, mas também pela rede de relações e interações que estabelece, envolvendo agentes internos e externos, viabilizando o suprimento de insumos e a distribuição de produtos.

O Planejamento Colaborativo consiste na interação de informações relativas a previsão de vendas e aos planos de suprimento, com o objetivo de aumentar a eficiência das cadeias logísticas do fornecedor e do cliente, possibilitando a diminuição de prazos, estoques e a melhoria do nível de serviços. Por meio deste planejamento compartilhado, torna-se possível sincronizar o ciclo de compras do cliente com o ciclo de produção do fornecedor (Arozo, 2002). Um sistema integrado de produção e venda tem como objetivos: (i) a redução e adequação do estoque de produtos; (ii) a contração do lead time de produção; (iii) a criação de um sistema de produção de pequenos lotes; e (iv) a redução do custo de distribuição física (Kobayashi, 2000).

Assim $_{2}$ introduz-se um novo conceito à Cadeia de Suprimentos, que é a Cadeia de Demanda. A Cadeia de Demanda transfere a demanda do mercado para os fornecedores. Estas 
duas cadeias formam a Cadeia de Suprimento-Demanda. Segundo Arozo (2002) ${ }_{\star}$ as vantagens desta nova postura são: a) Possibilidade de realização do planejamento de produção e distribuição em função da demanda final, sendo possível inclusive ações em conjunto com o cliente; b) Possibilidade de trabalhar de forma mais estável, já que se têm informações da demanda final, não contaminada por reações especulativas. Com isto, pode-se realizar melhor controle da produção e estoques; c) Para os clientes, a vantagem do comprometimento do fornecedor em termos de nível de serviço e redução de preços a longo prazo; e d) Possibilidade de redução de estoque, principalmente do estoque de segurança, por parte dos clientes, tendo em vista a segurança do fornecimento.

Para a formação de relacionamentos de cooperação na cadeia de suprimentosdemanda, é preciso que os executivos reconheçam sua dependência do conjunto. Essa dependência motiva a disposição para negociar "a transferência entre as funções, compartilhar informação-chave e participar do planejamento operacional em conjunto" (Bowersox e Closs, 2001). Segundo Spekman, Kamauff \& Myrh (1998), para se passar da categoria de fornecedor para parceiro de uma cadeia, existem alguns estágios pelos quais a organização deve passar. Estes estágios são os seguintes: (i) negociações de mercado, caracterizadas por relacionamento antagônico e discussões baseadas em preço; (ii) cooperação, caracterizada por poucos fornecedores e contratos de longo prazo; (iii) coordenação, caracterizada por trocas de informações, processamento via EDI (Electronic Data Exchange); e (iv) colaboração, que exige integração na cadeia, planejamento conjunto e troca de tecnologias. Os autores alertam que, para mudança de estágio, é necessário que se transforme o modo de pensar e orientação estratégica entre os participantes.

Em redes de relacionamento colaborativas, o desafio é fazer com que todos os membros da cadeia, incluindo fornecedores, produtores, distribuidores e consumidores, trabalhem de modo integrado, como se fizessem parte da mesma organização. Uma visão 
míope da cadeia reforça os problemas, tornando mais difícil a sua eliminação. Segundo Ellram e Krause (1994), o estabelecimento de parcerias entre empresas, visando à constituição de cadeias de relacionamento, requer o compromisso por períodos longos, com a troca mútua de informações e os riscos e recompensas deste relacionamento.

Segundo Walker (1998), para transformar uma operação logística centrada na organização individual em uma baseada na rede colaborativa, deve-se seguir um modelo com os seguintes passos: 1) Construir uma infra-estrutura de comunicação, sistemas e processos entre as organizações que se propõem a trabalhar em parceria; 2) Sincronizar continuamente a demanda capturada no ponto de venda com as decisões de oferta ao longo de toda a cadeia de suprimentos; 3) Gerenciar a logística global da rede para que se assegure que o produto esteja sempre se movendo, tanto na direção do consumidor, quanto na logística reversa; e 4) Implantar indicadores chave de mensuração, para garantir a satisfação do consumidor final.

\section{A INTEGRAÇÃO TECNOLOGIA DE INFORMAÇÃO E LOGÍSTICA}

A competição entre as empresas, em um ambiente globalizado, exige custos reduzidos, prazos curtos no ciclo do pedido, redução de estoques e maior qualidade do serviço logístico. Para conseguir melhorar o nível de serviço e reduzir custos simultaneamente, as empresas estão utilizando em larga escala a tecnologia da informação (Novaes, 2002). Na atual fase da logística, há um intenso intercâmbio de informações.

A constante pressão vinda das mudanças do mercado global tem levado a que o relacionamento tradicional entre a cadeia de suprimentos e a demanda sofra várias mudanças radicais. Nos últimos anos, a Tecnologia de Informação (TI) gerou um aumento na performance dos sistemas e um correspondente declínio no custo. Isto, combinado a uma continuada expansão da rede de comunicações global, permitiu que as empresas líderes criassem uma enorme vantagem competitiva (Cash \& Konsynski, 1985; Kekre \& Mudhopadhyay, 1992). A proliferação dos sistemas informatizados, o desenvolvimento dos 
sistemas de comunicações permitiu que, através de uma ligação de diversos processos, tecnologias, aplicações e estratégias de negócios, fosse criada uma base que possibilita às empresas coordenar suas transações diárias com seus diversos parceiros de negócios. Como resultado final, tem-se a criação de melhores processos de gerenciamento dos negócios, que reordenaram a cadeia de relacionamentos suprimentos- demanda. (Taylor \& Berg, 1995).

A demanda e o planejamento de suprimentos se apóiam em tecnologias tais como CRM (Customer Relationship Management), ERP (Enterprise Resource Management) e SCM (Supply Chain Management). Tradicionalmente o SCM (sob ponto de vista da aquisição) e o CRM (pela ótica de vendas) estiveram direcionados para redução de custos e vendas respectivamente. Hoje, a proposta mudou e ambos estão se reordenando para servir como um modo de aumentar a lucratividade, apoiados pelas capacidades transacionais dos sistemas ERP.

Haley e Krishnam (1995) acreditam que a Logística é a função que mais se beneficiou da automatização e redução dos custos permitida pelo uso intensivo de computadores. Segundo os autores, a utilização da Tecnologia da Informação deixou de ter uma atuação eminentemente interna passando a desempenhar um papel fundamental na habilitação de alianças colaborativas entre as empresas. A utilização de sistemas de informações possibilita que as empresas respondam rapidamente aos movimentos do consumidor final (Webster, 1991). Contudo, com o aumento do volume de informações trocadas entre as organizações, o risco de erros é multiplicado.

A Tecnologia de Informação permite que as organizações colaborem de forma segura com os integrantes da rede de suprimentos, em qualquer lugar, a qualquer instante. Segundo Dias, Pitassi \& Jóia (2003), a utilização desta tecnologia traz os seguintes benefícios para a função Logística: 1) compartilhamento de informações instantâneas, permitindo que o produto esteja no cliente certo, na hora certa; 2) diminuição do tempo de desenvolvimento e 
lançamento de novos produtos, já que o desenvolvimento é compartilhado entre os parceiros; 3) permite que alterações nos produtos, níveis de estoque e promoções sejam comunicadas imediatamente, melhorando a competitividade de toda a rede estratégica; 4) facilita que iniciativas e programas como just in time, gestão conjunta de estoques e outras que aumentem a eficiência das operações sejam compartilhadas; 5) permite que o consumidor tenha em tempo real serviços como acompanhamento da carga ao longo da cadeia logística; 6) facilita o desenvolvimento de novos canais de venda em nível global; e 7) permite a redução dos estoques, evitando o elevado custo de oportunidade de capital.

Para Hong-Minh, Barker \& Naim (1999), o uso de Tecnologia de Informação permite a criação de melhores canais de comunicação, agilizando a troca de informações e acessibilidade a todos. No entanto, Hong-Minh, Barker \& Naim (1999) alertam que esta Tecnologia deve ser utilizada cuidadosamente e operada de maneira correta, para evitar que informações e dados incorretos serão compartilhados.

Shee, Tang \& Tzeng (2000) propõem uma modelagem para a interação suprimentosdemanda, que consiste em quatro fases: (i) estágio um (formulação do problema) - neste estágio formula-se a estrutura preliminar do relacionamento suprimentos-demanda, identificando as variáveis-chave e como estas se relacionam; (ii) estágio dois (solução dos problemas individuais) - os componentes da cadeia, o líder e os seguidores, devem, cada um de per si, desenvolver procedimentos para solução de seus problemas; (iii) estágio três (negociação e compromisso)- não apenas os participantes (líder e seguidores) devem fazer seus compromissos individuais sobre custo e qualidade, mas deve haver uma interação entre os participantes num processo de barganha, que resulta em otimizar as decisões, compartilhando trocas e entendimentos; e (iv) estágio quatro (pós-negociação)- nesta fase, os participantes devem decidir se continuam juntos ou não. Se houver falha no entendimento, as partes podem decidir terminar o processo ou reiniciá-lo desde o estágio um. 


\section{MERCADO DE GASES}

De acordo com Petro e Química (2002), os gases estão cada vez mais presentes no dia-a-dia da população, como na área hospitalar, alimentícia, têxtil, de combustíveis e até mesmo em lançamento de foguetes com empresas nacionais disputando o fornecimento de hidrogênio e oxigênio. $\mathrm{O}$ mercado de gases está intimamente relacionado aos níveis de desenvolvimento e produção industriais. Como os gases industriais são essenciais para as atividades a que se destinam, há uma forte correlação entre a demanda e o Produto Interno Bruto (PIB), além de uma elasticidade-preço reduzida. De forma geral, este setor apresenta taxas de crescimento que variam de 1,5 a duas vezes o aumento do PIB. Em 2001, o mercado mundial de gases industriais correspondeu a US\$ 34,5 bilhões (MELLO, 2003).

A indústria de gás industrial opera em um mercado darwiniano, no qual os princípios da seleção natural levam à sobrevivência apenas das empresas mais ajustadas às necessidades do cliente (PACHIONE, 2003). O mercado brasileiro corresponde à cerca de um bilhão de dólares, o que representa dois terços do mercado sul-americano (MELLO, 2003). O setor é dominado pela White Martins, subsidiária da empresa americana Praxair, seguida pela Air Liquide, Aga e Air Products.

Dentre os principais produtos da indústria de gases, destacam-se o gás carbônico, o nitrogênio, o oxigênio, o argônio, o acetileno, o hidrogênio e o hélio. A comercialização de gases industriais pode ser efetuada através de cilindros ou plantas on-site, localizadas na área do cliente. O segmento de gases industriais apresenta uma demanda diversificada, além de uma grande potencialidade de ampliação de mercado. Porém, é crescente o aumento da concorrência neste setor, que ainda sofre impactos gerados pelo elevado preço da energia elétrica. A fim de reduzir os gastos energéticos, as empresas de gases industriais estão investido fortemente na otimização de processos (PACHIONE, 2003). 
No setor de gases industriais, não existe uma diferenciação significativa entre os produtos. Dessa forma, para que determinada empresa retire de seus produtos o conceito de comoditização, esta deve primar pela qualidade de atendimento, agregando valor através de serviços. Isto requer uma rede de distribuição eficiente que permita um pronto atendimento ao cliente, pois alguns setores da cadeia produtiva não podem ficar sem produto de modo nenhum, sob pena de perdas de vidas (hospitais) ou perda total da produção (siderurgia). Ainda, uma rede de distribuição eficaz é importante para a redução de custos, uma vez que o custo de distribuição é parcela significativa do custo total. Depois do custo energético, a logística é o fator mais determinante na composição do custo do produto (PACHIONE, 2003).

A empresa analisada é uma importante integrante deste segmento, possuindo unidades de produção espalhadas por diversos estados brasileiros. Uma grande base de clientes é abastecida pela frota de caminhões-tanque, que fazem a integração entre as unidades produtoras e o cliente final. Atualmente não existe um sistema de gerenciamento na cadeia logística que integre a unidade produtora-distribuição-cliente, não sendo feita a monitoração em tempo real da frota, nem integração entre as unidades de produção e os clientes. A empresa pretende modernizar o sistema de logística de modo que haja maior integração entre as unidades produtoras e clientes. A implantação deste sistema permitirá diversas melhorias como: melhor programação das unidades produtoras, melhor roteiro de entrega, monitoração mais acurada do estoque de produto nos clientes e acompanhamento "on line", pelos clientes, das entregas programadas.

\section{PROPOSTA DE SOLUÇÃO A SER ADOTADA PELA EMPRESA}

A organização espera integrar toda a cadeia de suprimentos e demanda de clientes através de um moderno sistema de gerenciamento que utiliza tecnologias, tais como: utilização de satélite, Internet, sistema de monitoramento remoto de tanques, interligação 
entre as unidades produtoras de gases e a central de logística e interligação com os transportadores. A empresa pretende utilizar uma série de tecnologias existentes ou desenvolvê-las por meio de órgãos externos, atuando como uma integradora dos diversos agentes tecnológicos.

A empresa busca aumentar a velocidade de respostas e permitir a visualização do desempenho da cadeia por meio de modernas ferramentas para gerenciar e operacionalizar o processo de distribuição. Todos os veículos utilizados para o abastecimento serão dotados de uma unidade de GPS, permitindo seu rastreamento e acompanhamento em tempo real. Para garantir a entrega a todos os clientes abastecidos automaticamente, a empresa utilizará uma unidade de telemetria remota para enviar as informações sobre os níveis dos tanques em clientes para o centro de distribuição de líquidos. Para melhorar o atendimento para os clientes, cujo abastecimento é realizado por meio de pedidos, a empresa possui uma Central de Atendimento ao Consumidor, pela qual podem ser realizadas solicitações de entrega 24 horas do dia, 7 dias por semana.

Com a implantação deste sistema gerenciador em sua rede Suprimento-Demanda, a empresa acredita que obterá as seguintes vantagens: (i) melhor gerenciamento do estoque de segurança nos clientes, reduzindo riscos de perdas devido à falta de produto ou estoques excessivos; (ii) segurança no abastecimento; (iii) introduzir fator diferenciador no atendimento ao cliente, servindo como um atrativo de venda; (iv) redução de investimento em veículos, devido a melhor programação; (v) confiabilidade das informações pela utilização de dados mais confiáveis; (vi) possibilidade de acompanhamento das entregas via Internet pelos clientes; (vii) controle automático da frota através da utilização de satélite, facilitando a localização dos veículos; e (viii) integração com sistemas existentes de programação das unidades produtoras, adequando capacidade à demanda dos clientes. 
Através de uma rede integrada, a empresą pretende aprimorar seus processos logísticos, diferenciar seus serviços, conquistar mercado e reduzir seus custos. A empresa está consciente sobre a importância da logística para atender estes objetivos. Segundo o gerente de logística desta organização, sua missão não se resume à realização de entregas para a satisfação do cliente. Sua principal função é atingir uma relação ganha-ganha, na qual buscase oferecer um serviço melhor para o cliente e aumentar o faturamento da empresa simultaneamente. Para alcançar esta meta, a empresa está implantando um rígido controle sobre a qualidade de seus serviços através de indicadores de desempenho. O principal indicador utilizado pelo setor de operações logísticas é a razão entre peso transportado e distância percorrida $(\mathrm{kg} / \mathrm{km})$, pois se terá carga máxima transportada com o menor custo.

Vê-se a seguir o modelo que será desenvolvido pela empresa.

\section{Logística de Líquidos - Brasil - 2000}

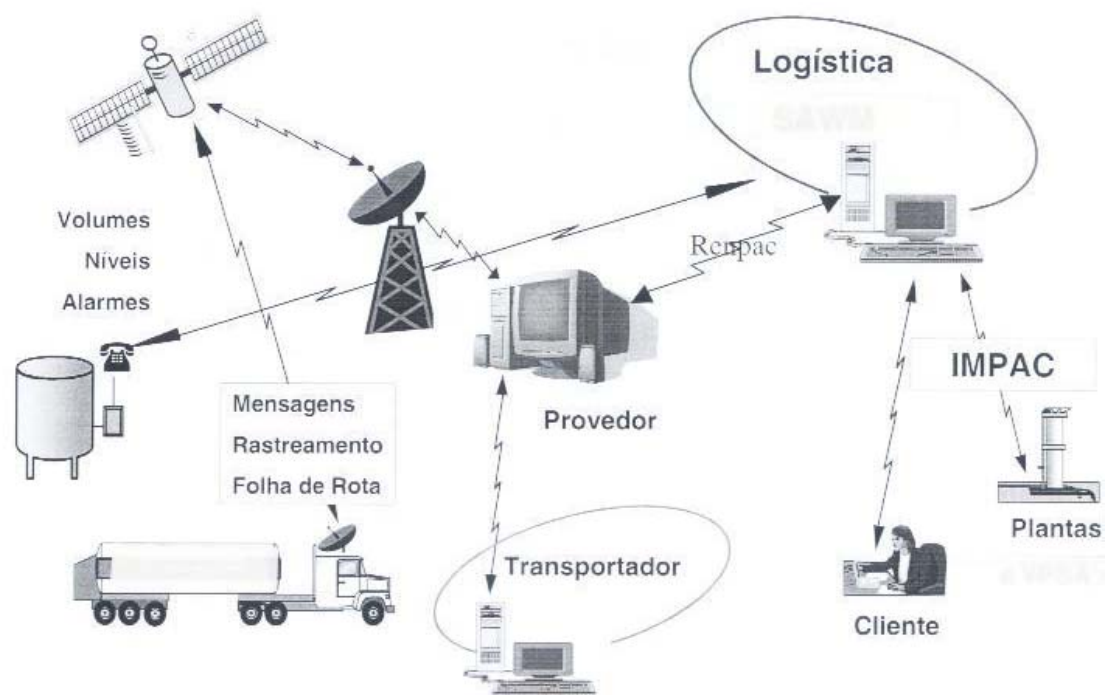

Figura 1: Proposta de integração suprimentos- demanda a ser implementada ( Fonte: autores, 2004). 
Passa-se, em seguida, para a análise da proposta de solução a ser adotada pela empresa. Como se trata de um projeto a ser desenvolvido pela empresa, não serão feitos comentários sobre os aspectos técnicos ou tecnológicos, e sim sobre a proposta apresentada, dentro dos conceitos acadêmicos enunciados anteriormente. Será analisado o conceito estratégico que sustenta as decisões para implantação.

\subsection{Comentários sobre a proposição apresentada pela empresa}

A empresa estudada procura seguir as mais modernas técnicas da administração e encontra-se atualizada, em seu posicionamento estratégico, em relação à Cadeia SuprimentosDemanda. Conforme sugerem diversos autores (Henriott, 1999, Pitassi \& Macedo Soares, 2002), a empresa está repensando seu modelo de gestão empresarial, além de procurar olhar a cadeia de suprimentos como um todo, que envolve todas as relações clientes-fornecedores, segundo recomenda Slack (1997).

Como sugere Aquino Campos (2003), a empresa busca integrar toda a cadeia logística e, com isto, aumentar o nível de serviço. Essa integração permitirá a redução dos estoques, o aumento da segurança e a melhoria da gestão do estoque de segurança, como preconiza Ballou (2001). Assim, a implantação do sistema integrado permitirá que se consolide a opção pelo nível de serviço, dentro da filosofia de Slack (1997) e as principais fontes de incerteza para o processo logístico, citadas por Aquino Campos (2003), serão minimizadas. Poderá ser criado, ainda, um banco de dados para permitir a obtenção de uma série de indicadores para cada um de seus produtos. Também serão atendidas as prescrições de Arozo (2002), já que haverá medições que permitirão a integração das necessidades dos clientes ao ajuste da produção.

A proposta da empresa é de que sejam utilizadas modernas ferramentas de informação, como Internet e outras, permitindo o aumento da velocidade de respostas e o acompanhamento em tempo real, o que atende Relvas (1996), além de possibilitar a 

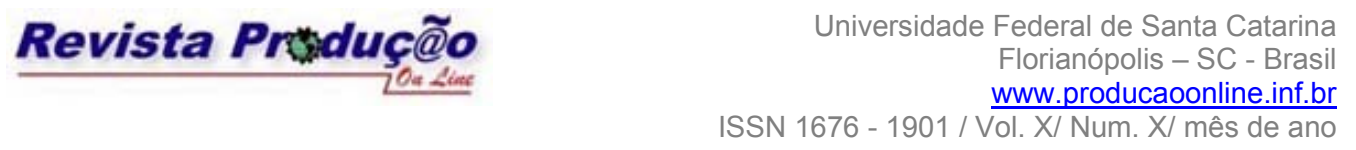

visualização do desempenho da cadeia e agregar valor, como Taylor e Berg (1995) recomendam. É importante ressaltar que os obstáculos listados por Mason-Jones e Towil (1998) em relação ao fluxo de informações para o cliente e para o fluxo físico de materiais poderão ser observados. Será aproveitada uma melhor integração entre Logística e Tecnologia da Informação, atendendo a todos os cuidados listados por Dias et al. (2003).

A empresa está iniciando um Planejamento Colaborativo com os clientes, tornando possível a sincronização do ciclo de compras com o seu ciclo de produção, atingindo os objetivos dos estudos de Arozo (2002). O sistema a ser implantado coloca a Logística como centro de toda a integração com os clientes, seguindo estudiosos como Christopher (1997). Contudo, ainda há pontos que podem ser melhorados, de modo que o processo de integração do sistema proposto pode e deve ser otimizado. Em seguida, apresenta-se como estas oportunidades de melhoria podem ser introduzidos, procurando a otimização do rendimento do sistema.

\subsection{Premissas para otimização}

Sugere-se que, inicialmente, a empresa realize uma avaliação de sua cadeia de suprimentos -demanda para descobrir os problemas existentes, sua natureza e causas. Devemse conhecer as bases reais dos problemas e estudá-los com profundidade, de maneira a resolvê-los, aprimorando assim, a efetividade da cadeia. Se os problemas e fontes de perdas forem visíveis e mensuráveis, fica mais fácil identificar as causas e eliminá-las. Em seguida, os processos devem ser redesenhados e os métodos de controle devem ser re-configurados, estabelecendo-se mecanismos de melhoria contínua.

Recomenda-se, também, que a especificação do modelo a ser implantado seja precedida pelo estudo dos processos de gestão e da estrutura da organização, seguindo o modelo proposto por Hammer e Champy (1993). Ao estudar estes processos, não devem ser considerados apenas os processos internos, mas também os pontos de integração com os 


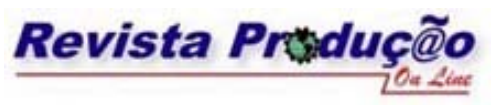

parceiros externos. Deve sempre ser priorizado o desenho dos processos de gestão e fluxos de informação que definem os vários parceiros da cadeia. Eșses processos podem ser desenhados através da reengenharia dos processos ou do lean thinking, que considera a cadeia de valor análoga ao processo de negócio.

Durante a implantação deste modelo, é indispensável que a alta direção, tanto da empresa quanto dos parceiros, esteja comprometida em reduzir as resistências ativa ou passiva. As pessoas envolvidas na gestão da cadeia suprimentos-demanda devem entender que o mais importante é o atendimento do consumidor final. Ainda, a organização deve utilizar as informações disponibilizadas pelo sistema como entrada para o planejamento corporativo.

Uma outra melhoria significativa poderia ser obtida através da implementação de um programa de seleção de parceiros, com os quais a empresa irá compartilhar a cadeia de suprimentos-demanda. Este processo de escolha pode ser feito pelo modelo sugerido por Spekman et al.(1998), onde os potenciais parceiros são colocados numa matriz $2 \times 2$. No eixo horizontal verifica-se sua importância estratégica (baixa-alta) e na vertical a complexidade (baixa-alta). O sistema deve ser implantado com aqueles que estejam no quadrante alta/alta, ou seja, alta importância estratégica e alta complexidade, uma vez que a implantação de um sistema de cooperação na cadeia de suprimentos-demanda é muito dispendiosa e os parceiros devem ser bem selecionados. Este tipo de matriz facilita muito o processo de seleção.

A proposição apresentada pela empresa integra a cadeia produção-distribuiçãoclientes, porém, não há indicações de uma integração total com os fornecedores. O sistema proposto dá prioridade à distribuição de produtos aos clientes, porém não aborda o relacionamento entre a empresa e os fornecedores. Sugere-se, então, que esta integração seja contemplada no desenvolvimento do sistema, conforme proposto por Novaes (2002). 
Ressalta-se também $_{2}$ a importância da observação de indicadores gerenciais e operacionais na seleção e na avaliação permanente dos fornecedores e prestadores de serviço.

Outra sugestão, que contribuiria para a melhoria da distribuição, seria a implementação, por parte da empresa estudada, do conceito de Estoque Gerenciado pelo Fornecedor (Vendor Managed Inventory - VMI) para todos os clientes. Assim, os estoques dos clientes seriam gerenciados pela empresa fornecedora, trazendo uma maior eficiência na gestão do estoque de gases, um controle mais apurado de todo o processo logístico e uma redução nos custos logísticos. O maior desafio, contudo, é fazer com que todos os participantes da cadeia trabalhem de modo integrado. Para iss modelo sugerido por Walker (1998) e o modelo de integração Suprimentos-Demanda de Shee et al. (2000).

\subsection{Conclusões finais}

A implantação do sistema de gerenciamento Suprimentos-Demanda proposto pela empresa terá um papel vital na modernização do gerenciamento das relações entre empresa e seus clientes. Pode-se afirmar também que a organização está em sintonia com os modernos conceitos de gestão da cadeia, utilizando os mais recentes conceitos acadêmicos sugeridos para o setor.

A implantação de um relacionamento on demand, como a proposta apresentada pela empresa, traz vantagens para todos os participantes. Entretanto, é normal existir divergências entre as motivações dos integrantes. Desta forma, a organização deve estar preparada para enfrentar dificuldades no processo de implantação. Conforme exposto anteriormente, os parceiros para este sistema de cooperação devem ser selecionados de forma criteriosa e detalhada.

Modernos recursos de Tecnologia de Informação e a partilha das informações entre os participantes são importantes itens para o sucesso do modelo proposto pela empresa. Como 
a organização exercerá o comando da cadeia, esta deve assegurar que o rendimento total seja, de fato, melhor que a soma do rendimento das partes.

Enfim, a contribuição deste artigo está no fato de ilustrar como as ações de logística estão sendo tomadas e para que direção. Pode-se concluir que haverá muitas mudanças nesse sentido com o passar dos anos e as empresas que perceberem e se anteciparem a estas evoluções terão maior chance de sucesso.

\section{REFERÊNCIAS}

AQUINO CAMPOS, L. H. Gerenciamento da demanda. Setembro 2003. Disponível em < http://www.ietec.com.br/ietec/techoje/techoje/gestaoetecnologiaindustrial/2003/09/12/200 ... Acesso em 20/09/2004.

AROZO, RODRIGO. Implicações comerciais no processo de previsão de vendas: a questão meta versus previsão e a importância da força de vendas. 2002. Disponível em < http://www.coppead.ufrj.br/pesquisa/cel/new/fr-imp.htm > Acesso em 20/09/2004.

BALLOU, RONALD H. Logística empresarial : transportes, administração de materiais, distribuição física. São Paulo: Atlas, 1993.

CAMPBELL, ALEXANDRA. Buyer-supplier partnerships: flip sides of the same coin, Journal of business and industrial marketing, v.12, n.6,1997.

CASH, J. I.\& KONSYNSKI, B. R. IS redraws competitive boundaries, Harvard Business Review, vol.63,n.2, 1985.

COUNCIL OF LOGISTICS MANAGEMENT (2004).. Disponível em: $<\underline{\mathrm{http}}$ ://clm1.org/Website/AboutCLM/Definitions/Definitions.asp $>$ Acesso em: 13/12/2004.

COPACINO, WILLIAM C. The It-enabled supply chain: key to future success. Logistics management \& distribuition report,v.37,n.4,1998. 
COOPER,M.C. \& ELLRAM, L.M. Characteristics of supply chain managementand the implication for purchasing and logistics strategy. International journal of logistics management, 4 ( 2), 1993.

CRISTHOPHER, MARTIN. Logística e gerenciamento da cadeia de suprimentos. São Paulo: Pioneira, 1997.

DIAS, ROGERIO MATOS, PITASSI, CLAUDIO \& JOIA, LUIZ ANTONIO. Gestão integrada da cadeia de suprimentos. FGV, EBAPE, Rio de Janeiro: 2003.

DRUCKER, PETER. O futuro já chegou. Revista Exame: São Paulo, 22 março 2000.

ELLRAM, L. \& Krause, R. Supplier partnerships in manufacturing versus non-manufacturing firms, The international journal of logistics management,5(1), 1994.

FARIAS FILHO, J. R. Avaliação de Estudo de Casos Reais.UFF, Março, 2003.

FERGUNSON, BRAD R. Implementing supply chain management. Production \& inventory management journal,v.41,n.2, 2000.

FERRAES NETO, F. A logística em sistemas produtivos complexos- um estudo de caso no polo automotivo de Curitiba- dissertação ( mestrado em engenharia de produção)- Programa de pós- graduação em engenharia de produção, UFSC,2000.

FIGUEIREDO, R.S. \& ZANBOM, A.C. A empresa vista como um elo da cadeia de produção e distribuição. Revista de Administração, São Paulo, v.33, n.3, jul/set.1998.

GULATI, R., NORHIA, N. \& ZAHEER A. Strategic networks. Strategic management journal, v.21, 2000 .

HALEY GEORGE T., KRISHNAM It is time for CALM: computer aided logistics management. International journal of physical distribuition \& logistics management, v.25,n.4, 1995. 
HAMMER, M. \& CHAMPY, J. Reengineering the corporation, London, 1993.

HENRIOTT, LISA L. Transforming supply chains into e-chains. Supply chain management review, Special global supplement, 1999.

HONG-MINH, S.M., BARKER, R. \& NAIN, M.M. Construction supply chain trend analysis, Proceedings IGLC7, University of California,Berkeley, USA, 1999.

KEKRE,S.\& MUDHOPADHYAY, T. Impact of eletronic data interchange technology on quality improvement and inventory reduction programs: a field study. International journal of production economics, v.28,n.3,1992.

KOBAYASHI, S. Renovação da logística, como definir estratégias de distribuiçao física global. São Paulo: Atlas, 2000.

LAMBERT, D.M., STOCK, J.R. \& ELLRAM, L.M. Fundamentals of logistics management.New York: Irwin- McGraw Hill, 1998.

MASON-JONES, R., TOWILL, D.R. Time compression in the supply chain: information management is the vital ingredient. Logistics information management, v.11, n.2,1998.

PITASSI, CLÁUDIO, MACEDO-SOARES< T.D.L.V.A., The strategic relevance of information tecnology for the business to business organization. In. BALAS Conference. Proceedings of BALAS conference. San Diego, Ca: University of San Diego, 2001.

SKANK \& GOVINDARAJAN ( apud Relvas), 1996.

SLACK, N., CHAMBERS, S. \& JOHNSTON, R. Administração da produção. Atlas: São Paulo,1997.

SHAPIRO, J.F., SINGHAL, V.M.\& WAGNER, S. N. Optimizing the value chain, Interface 23,1993 
SHEE, D.Y., TANG T.I. \& TZENG, G.H. Modeling the supply- demand interaction in electronic commerce; a bi-level programming appoach. Journal of electronic commerce research, v.1, n.2, 2000.

SPEKMAN, Robert E., KAUMAUFF, John W. \& MYHR, N. An empirical investigation into supply chain management. Supply chain management, v.3,n.2,1998.

STOCK, J.R. \& LAMBERT, D.M. Strategic logistics management, Homewood: Richard d. Irwin and Company, 1987.

TAYLOR, D.\& BERG, T. The business value of electronic commerce. Strategic analysis report, Gartner group, 1995.

VERGARA, SYLVIA C .Projetos e relatórios de pesquisa em administração. São Paulo: Atlas,2000.

WALKER, WILLIAM T. The supply chain- centric enterprise. Supply chain management review, summer 1998.

WEBSTER, FREDERICK E. Industrial marketing strategy, New York: John Wiley and Sons, 1991.

WILLIAMS, L., NIBBS, A, \& IRBY, D. Logistics integration; the effect of information technology, team composition and corporate competitive positioning. Journal of business logistics, v.18, n.2, 1997. 